\title{
ESTUDO DOS IMPACTOS DA RESOLUÇÃO NORMATIVA N 414/2010 - ANEEL NO CENTRO REGIONAL DE SERVIÇO NA EMPRESA CEMAT EM TANGARÁ DA SERRA - MT
}

\author{
Aparecido Marcio Pereira ${ }^{1}$ \\ Adervaldo Chaves Ribeiro ${ }^{2}$
}

\section{RESUMO}

O artigo teve como objetivo analisar o impacto da implantação da Resolução Normativa $n^{\circ}$ 414/2010 no Centro Regional de Serviço em Tangará da Serra - MT denominado CRS - TS , comparando os anos 2010 e 2011, composto por 27 (vinte e sete) municípios, com extensão de 243.113,5 $\mathrm{Km}^{2}$. Para identificação dos impactos foi utilizado análise documental dos relatórios fornecidos pela Cemat e entrevistas realizadas com a Gerência. Foram identificadas as principais mudanças na Resolução e o que impactou no CRS - TS: os prazos de vistoria e ligação de novas unidades consumidoras, cortes no fornecimento de energia elétrica, religações de unidades consumidoras e obrigatoriedade de aberturas de novos postos de atendimento ao público nas áreas de concessões. Os resultados mostraram que houve um impacto financeiro para a empresa Cemat, tendo como ponto de maior investimento a abertura de novos postos de atendimentos presencial, que por sua vez pode trazer maior satisfação do cliente que passou a ter um representante da empresa no seu município.

Palavras-chave: Atendimento. Concessão. Serviço Público. Qualidade.

\section{INTRODUÇÃO}

O Brasil vem passando por várias mudanças e uma delas é no setor elétrico. No mundo moderno a energia elétrica é indispensável para o progresso econômico e o desenvolvimento de uma sociedade (ANEEL, 2008).

O estado do Mato Grosso nas últimas décadas, assumiu um papel de destaque no cenário nacional por apresentar elevados índices de crescimento econômico, na produção agrícola e pecuária. Pacievitchv (2008) afirma que “O parque industrial é pequeno, porém nos últimos anos têm sido grandes os incentivos para que novas indústrias se estabeleçam na região," tendo em vista que a capital do estado Cuiabá, receberá jogos de futebol da Copa do Mundo de 2014 (FIFA, 2012).

Segundo a empresa EPE (2012) o ser humano encontra-se em uma fase de consumismo crescente de aparelhos elétricos, eletrônicos e a energia elétrica é peça

\footnotetext{
1 Acadêmico do curso de Ciências Contábeis da Unemat - Campus de Tangará da Serra, e-mail: ampereira22@gmail.com

2 Especialização em Finanças e Gestão Empresarial (2002) e Mestrado em Gestão de Empresa (2009), Atualmente Contador, Supervisor de Recursos Humanos e Professor na Área de Contabilidade na Universidade do Estado de Mato Grosso - Unemat - Campus de Tangará da Serra, e-mail: adervaldoribeiro@ gmail.com
} 
Estudo dos impactos da Resolução Normativa no 414/2010 - ANEEL no centro regional de serviço na empresa CEMAT em Tangará da Serra - MT

Adervaldo Chaves Ribeiro

fundamental para que esta etapa continue existindo. No entanto é importante ressaltar que para as distribuidoras de energia elétrica não basta somente fornecer a energia, as mesmas possuem por obrigação fornecê-la com qualidade e sem constantes interrupções até o ponto de entrega do cliente, pois a continuidade e qualidade da energia elétrica é o que garante que os consumidores não sejam prejudicados com aparelhos danificados (ANEEL-PRODIST, 2011).

Segundo Pires (1999, p. 140) “o modelo institucional estatal, vigente desde 1964, permaneceu praticamente inalterado nos 30 anos posteriores".

Vanzella (2003, p. 15) destaca que;

\begin{abstract}
Através da Lei no 8.631/93, que "dispõe sobre a fixação dos níveis das tarifas para o serviço público de energia elétrica, extingue o regime de remuneração garantida", foram iniciadas reformas no setor elétrico, à eliminação das tarifas unificadas no território nacional, e à instituição da recuperação tarifária. A partir de 1995, através da Lei $\mathrm{n}^{\circ}$ 8.987/95, que "dispõe sobre o regime de concessão e permissão da prestação de serviços públicos" e da Lei 9.074/95, que "estabelece normas para outorga e prorrogações das concessões e permissões de serviços públicos" foram introduzidas mudanças mais significativas, estabelecendo nova realidade: desverticalização de empresas, licitações de concessões, livre acesso às linhas de transmissão, criação da figura do produtor independente, implantação de novo órgão regulador do setor elétrico, participação do setor privado e o mercado deixa de ser exclusivo.
\end{abstract}

Conforme a Lei ${ }^{\circ}$ 9.427, de 26 de dezembro 1996;

Art. $1^{\circ}$ É instituída a Agência Nacional de Energia Elétrica - ANEEL, autarquia sob regime especial, vinculada ao Ministério de Minas e Energia, com sede e foro no Distrito Federal e prazo de duração indeterminado.

Art. $2^{\circ}$ A Agência Nacional de Energia Elétrica - ANEEL tem por finalidade regular e fiscalizar a produção, transmissão, distribuição e comercialização de energia elétrica, em conformidade com as políticas e diretrizes do governo federal.

$\mathrm{Na}$ ata da audiência pública 007/99, realizada em 5 de novembro de 1999, considerando as sugestões recebidas, juntamente com representante de: organizações sindicais, grandes consumidores de energia elétrica e organizações de defesa do consumidor, a Aneel estabeleceu a partir de 29 de novembro a Resolução Normativa $n^{\circ}$ 456/2000, que vigorou durante 10 anos.

Em 15 de setembro de 2010 foi publicado no Diário Oficial da União a nova Resolução Normativa ${ }^{\circ}$ 414/2010 vigorando a partir de março de 2011, estabelecendo novas condições gerais de fornecimento de energia elétrica, cujas disposições devem ser observadas pelas concessionárias de energia elétrica e consumidores. Esse processo foi iniciado em 2008, 
Estudo dos impactos da Resolução Normativa no 414/2010 - ANEEL no centro regional de serviço na empresa CEMAT em Tangará da Serra - MT

por meio de audiências e consultas públicas com consumidores, associações do setor elétrico, Ministério Público Federal, órgãos de defesa do consumidor e Ministério da Justiça (ANEEL - RESOLUÇÃO NORMATIVA - No 414/2010, p. 1).

Diante deste contexto, se propôs o seguinte questionamento: Quais os principais impactos da Resolução Normativa de no 414/2010 - Aneel no Centro Regional de Serviço na empresa Cemat de Tangará da Serra - MT?

Dessa forma, o estudo apresenta como objetivo analisar o impacto da implantação da Resolução Normativa $n^{\circ}$ 414/2010 e levantamento dos custos para instalação de novos postos de atendimento ao público no CRS - TS, tendo como comparativo os anos de 2010 e 2011.

Especificamente, identificar e mensurar os informes a respeito do cumprimento no atendimento dos prazos da Resolução $n^{\circ}$ 414/2010, verificando se houve violações nos prazos e levantamento dos custos para aberturas de novos postos de atendimento ao público.

O artigo se justifica pela importância de conhecer os impactos da nova Resolução 414/2010 dentro da estrutura de atendimento existente na empresa, pois até o momento não havia nenhum estudo científico sobre o assunto no Centro Regional de Serviço Cemat Tangará da Serra - MT.

Foi de fundamental importância para a formação do acadêmico no desenvolvimento e crescimento educacional, proporcionando ao mesmo aprendizado pela aplicação na prática de conhecimentos teóricos durante o período do curso em Ciências Contábeis.

Sabendo que o trabalho de conclusão de curso proporciona ao acadêmico uma análise de tudo o que aprendeu durante o curso, analisando situações concretas e reais dentro de uma organização, proporcionando uma visão real dos conceitos teóricos da contabilidade e assim o acadêmico poderá ampliar seus conhecimentos.

\section{REFERENCIAL TEÓRICO}

\subsection{LEGISLAÇÃO}

\subsubsection{Aneel - Agência Nacional de Energia Elétrica}

A Aneel foi instituída através do Decreto de Lei no 2.335, de 06 de outubro de 1997, sob o título "Constitui a Agência Nacional de Energia Elétrica - ANEEL, autarquia sob 
Estudo dos impactos da Resolução Normativa no 414/2010 - ANEEL no centro regional de serviço na

empresa CEMAT em Tangará da Serra - MT

Aparecido Marcio Pereira

Adervaldo Chaves Ribeiro

regime especial, aprova sua Estrutura Regimental e o Quadro Demonstrativo dos Cargos em

Comissão e Funções de Confiança e dá outras providências".

Aneel publicou uma cartilha de informação de utilidade pública: Por Dentro da Conta de Luz, (2008, p. 9 - 27) diz:

\begin{abstract}
Missão da Aneel: É proporcionar condições favoráveis para que o mercado de energia elétrica se desenvolva com equilíbrio entre os agentes e em beneficio da sociedade.(...)

Aneel é sistematicamente fiscalizada pela Controladoria Geral da União (CGU), pelo Tribunal de Contas da União (TCU) e pela Comissão Temática do Congresso Nacional (CTCN). Além desses controles, a Aneel é chamada, esporadicamente, a prestar informações ao Ministério Público e ao Poder Judiciário. A Aneel fiscaliza as concessionárias de energia elétrica, garantido o cumprimento das obrigações legais e contratuais pelas empresas do setor elétrico. As ações de fiscalização são permanentes, de acordo com calendário anual fixado. Dois importantes itens são avaliados durante as fiscalizações da Aneel nas distribuidoras: o aspecto econômicofinanceiro e a qualidade do fornecimento de energia elétrica.
\end{abstract}

\title{
2.2 CONCESSÕES E SERVIÇOS PÚBLICOS
}

Para Meirelles (1998, p. 325), "Concessão é a delegação contratual da execução do serviço, na forma autorizada e regulamentada pelo Executivo".

O Congresso Nacional decreta a Lei das Concessões de $n^{\circ} 8.987 / 95$, de 13 de fevereiro de 1995, que diz:

\begin{abstract}
Art. $2^{\circ}$ Para os fins do disposto nesta lei, considera-se:
I - Poder concedente : a União, o Estado, o Distrito Federal ou o Município, em cuja competência se encontre o serviço público, precedido ou não da execução de obra pública, objeto de concessão ou permissão;

II - concessão de serviço público: a delegação de sua prestação, feita pelo poder concedente, mediante licitação, na modalidade de concorrência, à pessoa jurídica ou consórcio de empresas que demonstre capacidade para seu desempenho, por sua conta e risco e por prazo determinado;

III - concessão de serviço público precedida da execução de obra pública: a construção, total ou parcial, conservação, reforma, ampliação ou melhoramento de quaisquer obras de interesse público, delegada pelo poder concedente, mediante licitação, na modalidade de concorrência, à pessoa jurídica ou consórcio de empresas que demonstre capacidade para a sua realização, por sua conta e risco, de forma que o investimento da concessionária seja remunerado e amortizado mediante a exploração do serviço ou da obra por prazo determinado;
\end{abstract}

Contudo, é frequente o conflito entre os interesses público e privado que surgem da diferença entre o objeto e objetivo principal. Empresas privadas: o lucro, o do interesse público: serviços adequados e tarifas menores, o interesse privado não pode ser maior que a supremacia do interesse público. Ou melhor, tendo interesses diferentes o que prevalecerá é o de interesse público. 
Estudo dos impactos da Resolução Normativa n 414/2010 - ANEEL no centro regional de serviço na

empresa CEMAT em Tangará da Serra - MT

Aparecido Marcio Pereira

Adervaldo Chaves Ribeiro

Sobre os serviços de utilidades públicas Kohama (2006, p. 5) destaca:

Os serviços de utilidades públicos que comumente são objeto de delegação através de contrato de concessão são: os de transportes coletivos, fornecimento de energia elétrica, abastecimento de água, de navegação aérea, comunicação telefônicas, radiodifusão, exploração de jazidas e fontes minerais, a utilização de terrenos nos cemitérios com túmulos de família, a instalação de indústrias de pesca às margens de rios e outros.

\subsubsection{O Contrato de Concessão}

Meirelles (1998, p. 331) entende que, “O Contrato de concessão é o documento escrito que encerra a delegação do poder concedente, define o objeto da concessão, delimita área, forma e tempo da exploração, estabelece os direitos e deveres das partes e dos usuários do serviço".

Conforme Aneel (2012):

Os contratos de concessão assinados entre a Agência Nacional de Energia Elétrica Aneel e as empresas prestadoras dos serviços de transmissão e distribuição de energia elétrica, estabelecem regras claras a respeito de tarifa, regularidade, continuidade, segurança, atualidade e qualidade dos serviços no atendimento prestado aos consumidores. Da mesma forma, define penalidades para os casos em que a fiscalização da Aneel constatar irregularidades.

Di Pietro (1997, p. 69) cita, "os princípios tradicionais do contato, foram sendo superados pela idéia de que o serviço público não pode parar e, em consequência, que podem ser feitas alterações, em especial nas cláusulas financeiras, necessárias para permitir a continuidade do contrato".

\subsubsection{A Política Tarifária}

Conforme o art. $9^{\circ}$ da Lei $\mathrm{n}^{\circ} 8.987 / 95$, de 13 de fevereiro de 1995, onde decidiu os princípios da política tarifária dos contratos de concessão, descrito abaixo:

Art. $9^{\circ}$ A tarifa do serviço público concedido será fixada pelo preço da proposta vencedora da licitação e preservada pelas regras de revisão previstas nesta Lei, no edital e no contrato. (...)

$\S 3^{\circ}$ Ressalvados os impostos sobre a renda, a criação, alteração ou extinção de quaisquer tributos ou encargos legais, após a apresentação da proposta, quando comprovado seu impacto, implicará a revisão da tarifa, para mais ou para menos, conforme o caso. 
Estudo dos impactos da Resolução Normativa n 414/2010 - ANEEL no centro regional de serviço na empresa CEMAT em Tangará da Serra - MT

Adervaldo Chaves Ribeiro

$\S 4^{\circ}$ Em havendo alteração unilateral do contrato que afete o seu inicial equilíbrio econômico-financeiro, o poder concedente deverá restabelecê-lo, simultaneamente à alteração.

O equilíbrio econômico financeiro é a relação que estabelece, no momento da celebração do contrato com encargo assumido pelo contratado e a contraprestação assegurada pela administração. De um lado o serviço público deve funcionar no interesse geral e sob a autoridade da administração, que resulta, dentre outros direitos, o da prestação de serviços adequados. De outro lado existe a idéia de que a empresa capitalista executa o serviço visando tirar o máximo de proveito possível, tendo como consequência fundamental o direito a manutenção do equilíbrio econômico financeiro estabelecido no momento da manutenção do contrato (CAPUTO e ROSELLI, 2008).

\subsubsection{Prestação de Serviço Público Adequado}

Segundo a lei $n^{\circ} n^{\circ} 8.987 / 95$, de 13 de fevereiro de 1995, o contrato de concessão tem como contrapartida a obrigação do concessionário de prestar serviço público adequado, seja diretamente pelo Estado ou por meio de concessões, não podendo ignorar qualquer correção de eventuais contratos.

A lei $\mathrm{n}^{\circ} 8.987 / 95$, de 13 de fevereiro de 1995 , determinou no art. $6^{\circ}$ o direito do usuário de receber serviço adequado:

Art. $6^{\circ}$ Toda concessão ou permissão pressupõe a prestação de serviço adequado ao pleno atendimento dos usuários, conforme estabelecido nesta Lei, nas normas pertinentes e no respectivo contrato.

$\S 1^{\circ}$ Serviço adequado é o que satisfaz as condições de regularidade, continuidade, eficiência, segurança, atualidade, generalidade, cortesia na sua prestação e modicidade das tarifas.

Nos artigos $7^{\circ}$ e $31^{\circ}$, a Lei das concessões ainda dispõe que o serviço público adequado é um direito dos usuários e dever dos concessionários, transcritos:

Art. $7^{\circ}$ Sem prejuízo do disposto na Lei no 8.078 , de 11 de setembro de 1990 , são direitos e obrigações dos usuários:

I - receber serviço adequado; (...)

Art. $31^{\circ}$ Incumbe à concessionária:

I - prestar serviço adequado, na forma prevista nesta Lei, nas normas técnicas aplicáveis e no contrato; (...)

IV - cumprir e fazer cumprir as normas do serviço e as cláusulas contratuais da concessão; 
Estudo dos impactos da Resolução Normativa n 414/2010 - ANEEL no centro regional de serviço na empresa CEMAT em Tangará da Serra - MT

Aparecido Marcio Pereira

Adervaldo Chaves Ribeiro

Existem outras legislações que tratam dos conceitos de serviços públicos adequados.

Dentre elas podemos citar a Lei $\mathrm{n}^{\circ}$ 8.078, de 11 de setembro de 1990, conhecido como Código 
Estudo dos impactos da Resolução Normativa no 414/2010 - ANEEL no centro regional de serviço na empresa CEMAT em Tangará da Serra - MT

Adervaldo Chaves Ribeiro

de Defesa do Consumidor. O art. $22^{\circ}$ do Código de Defesa do consumidor dispõe sobre a prestação do serviço público com qualidade:

Art. $22^{\circ}$ Os órgãos públicos, por si ou suas empresas, concessionárias, permissionárias ou sob qualquer outra forma de empreendimento, são obrigados a fornecer serviços adequados, eficientes, seguros e, quanto aos essenciais, contínuos.

A melhoria contínua do desempenho global deve ser um objetivo permanente da concessionária de serviço público. Um sistema de gestão da qualidade fornece uma melhor estrutura contínua com o objetivo de aumentar a probabilidade da satisfação das partes interessadas. Os requisitos de serviço adequado nada mais são do que o princípio da qualidade dos serviços. (CAPUTO e ROSELLI, 2008).

\subsection{CEMAT - CENTRAIS ELÉTRICAS MATOGROSSENSES S.A}

A Cemat é a única concessionária de distribuição de energia elétrica para todo o estado de Mato Grosso, atendendo 1.040.781 (um milhão e quarenta mil e setecentos e oitenta e uma) unidades consumidoras em 141(cento e quarenta e um) municípios, beneficiando aproximadamente 3.000 .000 (três milhões) de habitantes, a uma população que está distribuída em uma área de 903.358 km² (Cemat - Relatório Administrativo - 2010). “A imensidão dessa área é, portanto um desafio diário aos gestores e as equipes da Cemat" (Silva 2012). A sede da empresa fica na cidade de Cuiabá - MT, criada em outubro de 1958, seu contrato de concessão é de $\mathrm{n}^{\circ}$ 003/1997 firmado entre a União, por meio da Agência Nacional de Energia Elétrica - Aneel, assinado em 11 de dezembro de 1997 tendo vigência até 2027 e podendo ser prorrogado por mais 30 (trinta) anos. Esse documento está disponível na página da Aneel na Internet (www.aneel.gov.br), no link "Informações Técnicas/Contratos de Concessão".

No site da Cemat (2012) informa que:

\footnotetext{
Missão: Prestar serviços de energia elétrica com responsabilidade social e ambiental, visando à satisfação dos clientes, colaboradores, fornecedores e acionistas, contribuído para o desenvolvimento do País.

Visão: Ser reconhecido como Grupo de excelência no setor de energia elétrica pelo serviço prestado, tecnologia empregada e qualificação dos colaboradores.

Valores:

- Integridade: respeito à moral, aos bons costumes, às leis, a si próprio e ao próximo.

. Competência: saber fazer, poder fazer e querer fazer.

. Excelência: fazer com grau de qualidade que o diferencie.
} 
Estudo dos impactos da Resolução Normativa no 414/2010 - ANEEL no centro regional de serviço na empresa CEMAT em Tangará da Serra - MT

- Responsabilidade: bem cumprir os deveres para com a sociedade, a família e a empresa.

- Criatividade: buscar soluções alternativas, inovadoras e originais (novos paradigmas).

\subsubsection{SGQ - Sistema de Gestão de Qualidade}

Qualidade: o conceito é relativo, mas a definição mais adequada é aquela que atenda a necessidade, quanto as especificações, prazos, preço e condições para pagamento ajustadas a do cliente indo além do esperado, encantando-o, não trocando-o por nada e que garanta resultados adequados para as demais partes interessadas como: Fornecedores, Parceiros e Sociedade (NBR ISO 9000 - 2005).

O sistema de gestão da qualidade pode ajudar as organizações a aumentar a satisfação do cliente. Clientes exigem produtos com características que satisfaçam as suas necessidades e expectativas. (...). Requisitos do cliente podem ser especificados contratualmente pelo cliente ou determinados pela própria organização. Em qualquer caso, será sempre o cliente que, em ultima análise, determinará a aceitabilidade do produto. Como as necessidades e expectativas dos clientes estão mudando, por causa das pressões competitivas e dos avanços tecnológicos, as organizações são induzidas a melhorar continuamente seus produtos e processos. (NBR ISO 9000 - 2005, p. 6).

Segundo a Resolução da Aneel nº 024/00, de 27 de Janeiro de 2000, publicou dizendo;

$\S 5^{\circ}$ Até 31 de dezembro de 2007, a concessionária de distribuição deverá certificar o processo de coleta dos dados e de apuração dos indicadores individuais e coletivos estabelecidos nesta resolução, com base nas normas da Organização Internacional para Normalização (International Organization for Standardization) ISO 9000.

Segundo Silva (2012) diante dessa Resolução da Aneel nº 024/00, a Diretoria da Cemat resolveu, mais que cumprir a legislação, trabalhar com todos seus processos possuindo um padrão de informações confiáveis e exatas, sendo que para isto implantou o Sistema de Gestão da Qualidade - SGQ, tendo como base a Associação Brasileira de Normas Técnicas e as Normas Brasileiras - ABNT NBR ISO 9000:2005.

Após a $657^{\mathrm{a}}$ reunião da comissão de certificação da Fundação Carlos Alberto Vanzolini, realizada no dia 28/09/2007, deliberou-se pela concessão da Certificação do Sistema de Gestão da Qualidade da organização Cemat, conforme norma e escopo seguintes:

A. Coleta, apuração, envio e gestão dos indicadores técnicos e comercias junto ao Órgão Regulador e suas Agências Estaduais;

B. Atividades de apoio relacionadas; 
Estudo dos impactos da Resolução Normativa n 414/2010 - ANEEL no centro regional de serviço na empresa CEMAT em Tangará da Serra - MT

Aparecido Marcio Pereira

Adervaldo Chaves Ribeiro

C. Relacionamento com Clientes (por meio da Ouvidoria) e o Órgão Regulador e suas Agências Estaduais;

D. Gestão dos processos de atendimentos e tratamento de reclamações de cliente. (Publisher Expert - Sistema Gerencial Para Gestão dos Indicadores de Qualidade Utilizado Pela Cemat).

Silva (2012) informou que para um melhor gerenciamento foi divido o Estado do Mato Grosso em 6 (seis) Centros Regionais de Serviços - CRS's: Barra do Garças, Cáceres, Sínop, Rondonópolis, Metropolitana (Cuiabá e Várzea Grande) e Tangará da Serra (Figura 1).

Figura1. Divisão do Estado do Mato Grosso em Centros Regionais de Serviços

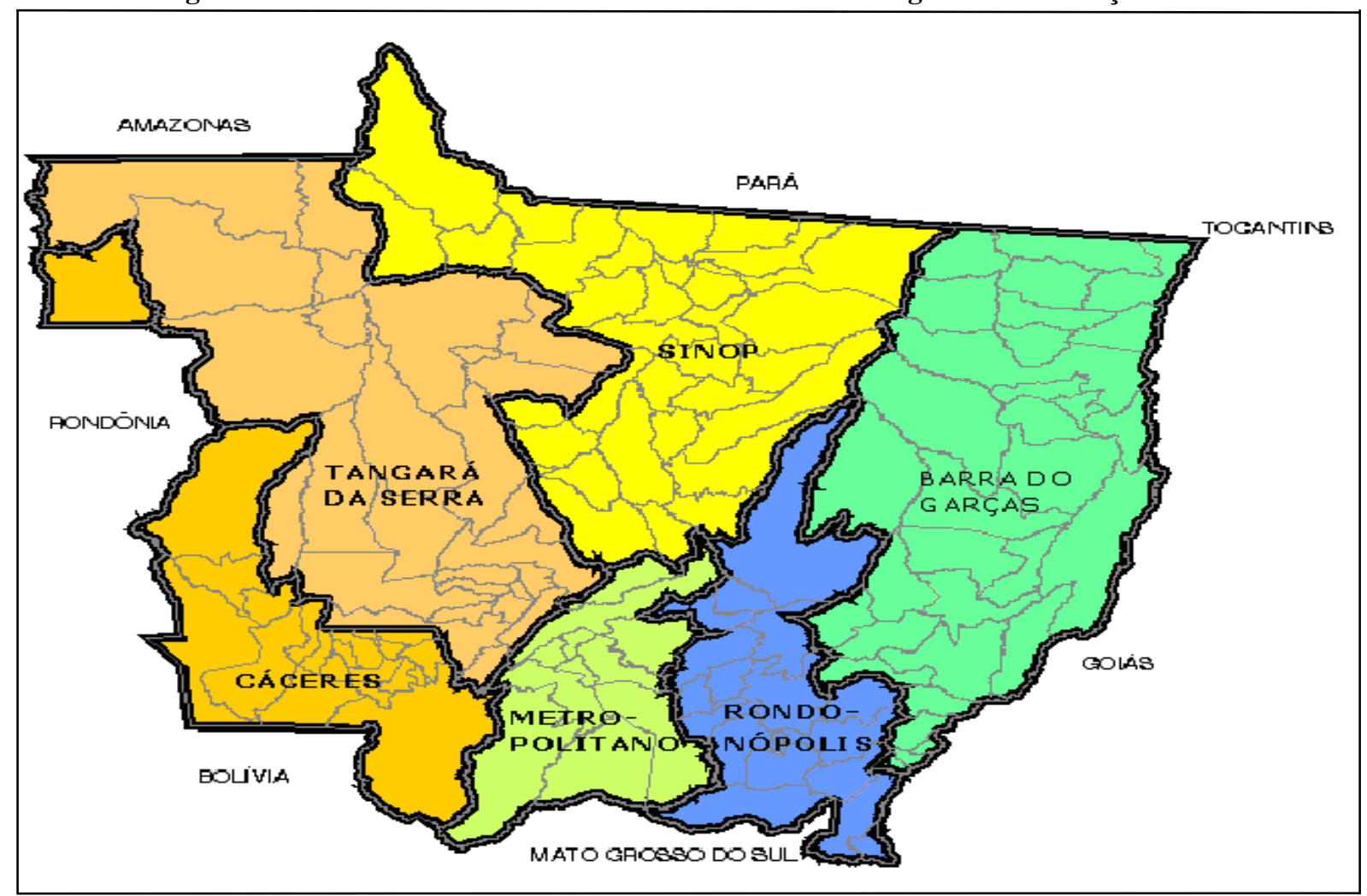

Fonte: Cemat, 2011.

2.3.2 CRS - TS - Centro Regional de Serviço de Tangará da Serra - MT

A pesquisa demonstrou que a área de atuação da Cemat é extensa, por isso teve como escopo o Centro Regional de Serviço de Tangará da Serra - MT, que é a maior regional da Cemat em uma área de atendimento, espalhadas por 243.113,5 Km² (Cemat - Relatório Administrativo - 2010) área maior que o estado do Paraná com 199.316,694 Km² (IBGE 2010), é composta por 27 (vinte e sete) municípios: Alto Paraguai, Arenápolis, Aripuanã, Barra do Bugres, Brasnorte, Campo Novo do Parecis, Campos de Júlio, Castanheira, Colniza, Cotriguaçu, Denise, Diamantino, Juara, Juína, Juruena, Nortelândia, Nova Marilândia, Nova 
Estudo dos impactos da Resolução Normativa no 414/2010 - ANEEL no centro regional de serviço na empresa CEMAT em Tangará da Serra - MT

Maringá, Nova Olímpia, Novo Horizonte do Norte, Porto dos Gaúchos, Porto Estrela, Santo Afonso, São José do Rio Claro, Sapezal, Tabaporã, Tangará da Serra.

$\mathrm{Na}$ análise dos relatórios, o Centro Regional de Serviço de Tangará da Serra - MT, fechou o ano de 2011 com 158.269 (cento e cinquenta e oito mil e duzentos e sessenta e nove) consumidores, um consumo de 480.18 Mwh (Mega Watts Horas), sendo arrecadado R\$ 344.551.439,12 (trezentos e quarenta e quatro milhões e quinhentos e cinquenta e um mil e quatrocentos e trinta e nove reais e doze centavos), com o quadro de 162 (cento e sessenta e dois) funcionários e 126 (cento e vinte e seis) terceirizados, tendo uma extensão redes elétrica de $3.603 \mathrm{Km}$ em Baixa Tensão (50 a 1.000 Volts) e $18.965 \mathrm{Km}$ em Média Tensão (acima de 1.000 a 36.200 Volts).

\subsubsection{Vistoria}

Conforme Resolução Normativa no 414/2010 "vistoria: procedimento realizado pela distribuidora na unidade consumidora, previamente à ligação, com o fim de verificar sua adequação aos padrões técnicos e de segurança da distribuidora" (ANEEL - RESOLUÇÃO NORMATIVA - No 414/2010, p. 10).

\section{METODOLOGIA}

Oliveira (1999, p. 57) afirma que metodologia "trata do conjunto de processos pelos quais se torna possível conhecer uma determinada realidade, produzir determinado objeto ou desenvolver certos procedimentos ou comportamentos".

Foi um estudo de caso e caracterizou-se como pesquisa exploratória de natureza bibliográfica, segundo Gil (1989, p. 45), “é aquela que não possui contornos claramente definidos, ou quando um problema é pouco conhecido tornando difícil formular hipóteses precisas”. Essa, reúne informações tão numerosas e detalhadas quanto possível. Por isso recorre a técnicas de coleta de informações variadas em fontes de pesquisa bibliográfica de: livros, dissertações, consultas na internet, revistas, documentos internos, resoluções normativas da Aneel.

As informações da pesquisa foram obtidas através de entrevistas aberta nãoestruturada, Silva e Menezes (2001, p. 33) explicam que "entrevistas não-estruturadas não existe rigidez de roteiro. Podem-se explorar mais amplamente algumas questões”. Então 
Estudo dos impactos da Resolução Normativa no 414/2010 - ANEEL no centro regional de serviço na empresa CEMAT em Tangará da Serra - MT

Adervaldo Chaves Ribeiro

foram entrevistados o gerente regional, os gerentes setoriais das unidades de serviços e os funcionários do CRS de Tangará da Serra - MT, a fim de obter informações que possam responder o objetivo específico da pesquisa. Foram feitas visitas In Loco nos departamentos para coletas de dados e análises dos relatórios dos sistemas Publisher Expert (Sistema Gerencial Para Gestão dos Indicadores de Qualidade Utilizado Pela Cemat) e Utilities Expert (UE - Sistema de Gestão Comercial e Técnico Utilizado Pela Cemat).

Assim Lakatos e Marconi (2010, p. 178), conceitua:

\begin{abstract}
Entrevista é um encontro entre duas pessoas, afim de que uma delas obtenha informações a respeito de terminado assunto, mediante uma conversação de natureza profissional. É um procedimento utilizado na investigação social, para a coleta de dados ou para ajudar no diagnóstico ou tratamento de um problema social.
\end{abstract}

A aplicação da metodologia foi realizada no Centro Regional de Serviço na empresa Cemat em Tangará da Serra - MT. O objeto de estudo é o impacto da implantação da Resolução Normativa n 414/2010 - Aneel, onde a mesma determina mudanças nos prazos de vistoria de ligação de novas unidades consumidoras, cortes no fornecimento de energia elétrica, religações de unidades consumidoras e obrigatoriedade de aberturas de novos postos de atendimento presencial ao público nas áreas de concessões.

Abordagem do problema foi usada de forma quantitativa a que segundo Ribeiro, Torres e Rocha (2006, p. 49) "caracteriza-se pelo emprego de instrumento estatísticos, tanto na coleta quanto no tratamento dos dados", o que significa traduzir em números, opiniões e informações para classificá-las e analisá-las. O pesquisador analisou os dados, conheceu o cenário do processo de implantação de novas agências de atendimento presencial ao público.

$\mathrm{O}$ período pesquisado foi de janeiro à março de 2012. A pesquisa tem como comparativo os anos de 2010 e 2011 na empresa Cemat no Centro Regional de Serviço de Tangará da Serra - MT.

\title{
4. DISCUSSÃO DOS RESULTADOS
}

\subsection{COMPARAÇÕES ENTRE AS RESOLUÇÕES NORMATIVAS DE Nº 456/2000 E A}

DE No 414/2010 - ANEEL

\subsubsection{Prazos de Vistoria da Unidade Consumidora}


Estudo dos impactos da Resolução Normativa no 414/2010 - ANEEL no centro regional de serviço na empresa CEMAT em Tangará da Serra - MT

Em 2010 a Cemat não media o indicador de vistoria, a unidade de serviço era vistoriada e ligada até com 5 (cinco) dias úteis, tanto na área urbana, como na área rural , sendo assim não cumprindo a Resolução Normativa nº 456/2000 (Tabela 1).

Com a determinação da Resolução Normativa n ${ }^{\circ}$ 414/2010, em 2011 a Cemat passou a medir o indicador de vistoria. Das 17.821 (dezessete mil e oitocentos e vinte e uma) vistorias realizadas (Quadro1), 14.222 (quatorze mil e duzentos e vinte e duas) vistorias, representadas por $79,80 \%$ são de área urbana, tendo o prazo de até 3 (três) dias úteis, onde somente $0,07 \%$ violaram esse prazo, representados por 10 (dez) unidades consumidoras. As da área rural foram no total de 3.599 (três mil e quinhentos e noventa e nove) vistorias em novas unidades consumidoras, representados por 20,20\%. Não tendo violação no prazo que são de 5 (cinco) dias úteis.

Tabela 1 - Comparação entre as Resoluções Normativas de N. $.^{\circ} 456 / 2000$ e da N. ${ }^{\circ}$ 414/2010

\begin{tabular}{c|c|c}
\hline ASSUNTO & Durante a n. ${ }^{\circ} \mathbf{4 5 6 / 2 0 0 0}$ - Aneel & Após a n. $^{\circ} \mathbf{4 1 4 / 2 0 1 0}$ - Aneel \\
\hline $\begin{array}{l}\text { Prazos de Vistoria da } \\
\text { Unidade Consumidora: }\end{array}$ & $\begin{array}{l}\text { Art. 30 } \\
\text { A vistoria de unidade consumidora, será } \\
\text { efetuada no prazo de 3 (três) dias úteis. } \\
\text { Tanto em área urbana, como na área } \\
\text { rural. }\end{array}$ & $\begin{array}{l}\text { A vistoria da unidade consumidora } \\
\text { deve ser efetuada em até 3 (três) dias } \\
\text { úteis na área urbana e 5 (cinco) dias } \\
\text { úteis na área rural. }\end{array}$ \\
\hline Tipo de Serviço & ANO 2010 & \multicolumn{1}{c}{ ANO 2011 } \\
\hline Quantidade de Vistoria & 0 & 17.821 \\
\hline
\end{tabular}

Fonte: $\mathbf{O}$ autor.

\subsubsection{Prazos de Ligação da Unidade Consumidora}

Em 2010 na empresa não havia indicadores separados das ligações de baixa tensão urbana e rural. A média era de até 5 (cinco) dias úteis para ligações das novas unidades consumidoras urbanas ou rurais, sendo assim não cumprindo a Resolução Normativa ${ }^{\circ}$ 456/2000. Nesse ano foram realizadas 15.454 (quinze mil e quatrocentos e cinquenta e quatro) novas ligações de unidades consumidoras (Tabela 2), sendo 15.230 (quinze mil e duzentos e trinta) ligações em baixa tensão (50 a 1.000 Volts) na área urbana e rural, o que representa 98,55\% desse tipo de serviço. Do total de ligações houve 1 (uma) violação no mês de dezembro de 2010, onde a unidade consumidora foi ligada com prazo máximo de 21 (vinte e um) dias. As outras 224 (duzentos e vinte e quarto) ligações são unidades de consumidores 
Estudo dos impactos da Resolução Normativa no 414/2010 - ANEEL no centro regional de serviço na empresa CEMAT em Tangará da Serra - MT

Adervaldo Chaves Ribeiro

industriais de média tensão (acima de 1.000 a 36.200 Volts), representado por 1,45\% do total, onde o prazo máximo de ligação era de 10 (dez) dias, não havendo violações, e tendo uma ligação realizada no prazo máximo de 10 (dez) dias em novembro de 2010.

Com a determinação da Resolução Normativa no 414/2010, em 2011 a Cemat passou a medir separadamente os indicadores de ligação na área urbana e rural. Sendo executadas 16.324 (dezesseis mil trezentos e vinte e quatro) novas ligações de unidades consumidoras (Tabela 2), o que representou um crescimento de 5,63\%, referente a 2010. Com analise separada dos indicadores, as ligações novas em área urbana foram de 11.919 (onze mil novecentos e dezenove) representando 73,01\%, onde o prazo máximo de ligação após vistoria é de 2 (dois) dias úteis (Tabela 2). Do total das ligações em área urbana, 6 (seis) foram ligadas com prazo de 3 (três) dias após vistoria, havendo desta forma a violação do indicador. Na área rural foram ligadas 4.164 (quatro mil e cento e sessenta e quatro), representando $25,51 \%$ do total, onde somente 1 (uma) ligação foi violada em 6 (seis) minutos. Os consumidores em média tensão (acima de 1.000 a 36.200 Volts), foram 241 (duzentos e quarenta e uma) ligações, representando $1,48 \%$ do total, onde o prazo de ligação é de 7 (sete) dias úteis, e para esta classe de cliente houve 1 (uma) violação no mês de setembro, sendo que a ligação ocorreu com 8 (oito) dias.

Tabela 2 - Comparação entre as Resoluções Normativas de N. ${ }^{\circ}$ 456/2000 e da N..$^{\circ}$ 414/2010

\begin{tabular}{|c|c|c|}
\hline ASSUNTO & Durante a n. ${ }^{\circ} 456 / 2000$ - Aneel & Após a n. ${ }^{\circ} 414 / 2010$ - Aneel \\
\hline $\begin{array}{l}\text { Prazos de Ligação da } \\
\text { Unidade Consumidora: }\end{array}$ & $\begin{array}{l}\qquad \mathbf{A r t . ~}^{\mathbf{2 7}^{\mathbf{0}}} \\
3 \text { (três) dias úteis para consumidores, em } \\
\text { área urbana; } \\
5 \text { (cinco) dias úteis para consumidores, } \\
\text { em área rural; e } \\
10 \text { (dez) dias úteis para consumidores } \\
\text { industriais, em área urbana ou rural. }\end{array}$ & $\begin{array}{l}\text { Art. } \mathbf{3 1}^{\mathbf{0}} \\
2 \text { (dois) dias úteis para consumidores, } \\
\text { em área urbana; } \\
5 \text { (cinco) dias úteis para os } \\
\text { consumidores, em área rural; e } \\
7 \text { (sete) dias úteis para consumidores } \\
\text { industriais, em área urbana ou rural. }\end{array}$ \\
\hline Tipo de Serviço & ANO 2010 & ANO 2011 \\
\hline Quantidade de Ligação & 15.454 & 16.324 \\
\hline
\end{tabular}

Fonte: $\mathrm{O}$ autor.

4.1.3 Prazos de Suspensão do fornecimento da Unidade Consumidora

No ano de 2010 a realização de cortes nas Unidades consumidoras podia ser a qualquer tempo após os 15 (quinze) dias decorridos do aviso de corte informado ao 
Estudo dos impactos da Resolução Normativa no 414/2010 - ANEEL no centro regional de serviço na empresa CEMAT em Tangará da Serra - MT

Adervaldo Chaves Ribeiro

consumidor. Neste ano foram realizados 36.551 (trinta e seis mil e quinhentos e cinquenta e um) cortes (Tabela 3), tendo o mês de maio o mês que se efetuou maior número de cortes 3.932 (três mil novecentos e trinta e dois), o que representou 10,76\% dos cortes efetuados.

Em 2011 a empresa passou a cumprir a Resolução Normativa n n $^{\circ}$ 414/2010 que não permite o corte de faturas em aberto com mais de 90 (noventa) dias, o que refletiu em uma redução significativa no número de cortes efetuados, que passou a ser de 32.248 (trinta e dois mil e duzentos e quarenta e oito) cortes no ano (Tabela 3). O mês de maior representatividade foi em fevereiro com 3.192 (três mil cento e noventa e dois) cortes, representando 9,90\%. Esta redução de cortes também reduz a entrada de receita para empresa.

Tabela 3 - Comparação entre as Resoluções Normativas de N. ${ }^{\circ}$ 456/2000 e da N. ${ }^{\circ}$ 414/2010

\begin{tabular}{|c|c|c|}
\hline ASSUNTO & Durante a n. ${ }^{\circ} 456 / 2000$ - Aneel & Após a n. $.^{\circ} 414 / 2010$ - Aneel \\
\hline $\begin{array}{l}\text { Prazos de Suspensão do } \\
\text { fornecimento da Unidade } \\
\text { Consumidora: }\end{array}$ & $\begin{array}{l}\text { Art. } \mathbf{9 1}^{\mathbf{0}} \\
\text { O Corte feito a qualquer tempo, } \\
\text { 15(quinze) dias após a } \\
\text { notificação. }\end{array}$ & $\begin{array}{l}\text { Art. } \mathbf{1 7 2}^{\mathbf{o}} \text { e } \mathbf{1 7 3}^{\mathbf{0}} \\
\text { Corte só poderá ser feito em horário } \\
\text { comercial, } 15 \text { (quinze) dias após a } \\
\text { notificação. Faturas em aberto, com mais } \\
\text { de } 90 \text { dias, não podem mais gerar corte, } \\
\text { desde que as posteriores estejam quitadas. }\end{array}$ \\
\hline Tipo de Serviço & ANO 2010 & ANO 2011 \\
\hline Qde. Susp. Fornecimento & 36.551 & 32.248 \\
\hline
\end{tabular}

Fonte: $\mathrm{O}$ autor.

\subsubsection{Prazos de Religação da Unidade Consumidora}

No ano de 2010 o CRS - TS, efetuou 47.981 (quarenta e sete mil e novecentos e oitenta e uma) religações de unidades consumidoras, tanto área urbana e quanto na área rural, todas com prazo máximo 48 (quarenta e oito) horas (Tabela 4). Neste ano houve 4 (quatro) violações de religações, que representaram $0,008 \%$ do total, sendo que destas violações a de maior tempo foi realizada com 53,59 horas, no mês de fevereiro/2010. Do total de religações efetuadas, 4.468 (quatro mil e quatrocentos e sessenta e oito) são de urgência que possuem prazo máximo de execução de 4 (quatro) horas, que representaram 9,31\%. Das 4.468 (quatro mil e quatrocentos e sessenta e oito) religações, 32 (trinta e duas) unidades consumidoras foram cortadas indevidamente, e também entraram no rol de serviços que foram necessário ser executados com 4 (quatro) horas. No ano de 2010 não teve violação do indicador. 
Estudo dos impactos da Resolução Normativa no 414/2010 - ANEEL no centro regional de serviço na empresa CEMAT em Tangará da Serra - MT

Com a implementação das diretrizes da Resolução Normativa nº 414/2010, em 2011 a Cemat passou a medir separadamente os indicadores de religações na área urbana e também na área rural. O CRS - TS, efetuou 43.030 (quarenta e três mil e trinta) religações de unidades consumidoras (Tabela 4), havendo desta forma uma redução de 10,32\% em comparação com 2010. Entre elas 36.757 (trinta e seis mil e setecentos e cinquenta e sete) religações, foram da área urbana representando $85,42 \%$, que passou a ter o prazo de 24 (vinte e quatro) horas para religação, para este indicador houve 4 (quatro) violações que representou 0,011\% do total tendo 1(uma) religação com maior tempo de atendimento 52,44 horas, no mês de janeiro. Na área rural foram efetuadas 6.273 (seis mil duzentos e setenta e três) religações, as quais possuem prazo de 48 (quarenta e oito) horas para o atendimento, sendo que no CRS - TS tevese 1 (uma) violação de prazo em 2,49 horas o que representou $0,016 \%$ do total no mês de julho. As religações de urgência continuaram com prazo de 4 (quarto) horas em área urbana (Tabela 4) e foram realizadas 4.414 (quatro mil e quatrocentos e quatorze) religações, dentre as quais foram violadas 6 (seis) ordens de serviço que representaram $0,14 \%$ do total, tendo como maior prazo 5,52 horas para atendimento no mês de março. Neste período ocorreram 135 (cento e trinta e cinco) cortes indevidos, que possui prazo para religar de 4 (quatro) horas na área urbana, deste total 18 (dezoito) unidades consumidoras foram religadas fora do prazo, tendo como maior prazo para atendimento 4,54 horas.

Tabela 4 - Comparação entre as Resoluções Normativas de N. ${ }^{\circ}$ 456/2000 e da N. ${ }^{\circ}$ 414/2010

\begin{tabular}{|c|c|c|}
\hline ASSUNTO & Durante a n. ${ }^{\circ} 456 / 2000$ - Aneel & Após a n. ${ }^{\circ}$ 414/2010 - Aneel \\
\hline $\begin{array}{l}\text { Prazos de Religações da } \\
\text { Unidade Consumidora: }\end{array}$ & $\begin{array}{l}\text { Art. } \mathbf{1 0 7}^{\circ} \mathbf{e} \text { Art. } \mathbf{1 0 8}^{\circ} \\
\text { Art. } \mathbf{1 0 7}^{\circ} \text {. } 48 \text { (quarenta e oito) horas, } \\
\text { para unidades consumidoras, após a } \\
\text { solicitação com a constatação do } \\
\text { pagamento, em área urbana ou rural. } \\
\text { Art. } \mathbf{1 0 8}^{\mathbf{0}} \text { Fica facultado à } \\
\text { concessionária implantar procedimento } \\
\text { de religação de urgência, caracterizado } \\
\text { pelo prazo de até } 4 \text { (quatro) horas. }\end{array}$ & $\begin{array}{l}\text { Art. }^{\mathbf{1 7 6}^{\circ}} \\
24 \text { (vinte e quatro) horas, para } \\
\text { unidades consumidoras, após a } \\
\text { solicitação com a constatação do } \\
\text { pagamento, em área urbana. } \\
48 \text { (quarenta e oito) horas, para } \\
\text { unidades consumidoras, em área } \\
\text { rural; } \\
4 \text { (quatro) horas, para religação de } \\
\text { urgência em área urbana; } \\
8 \text { (oito) horas, para religação de } \\
\text { urgência em área rural. }\end{array}$ \\
\hline Tipo de Serviço & ANO 2010 & ANO 2011 \\
\hline Quantidade Religação & 47.981 & 43.030 \\
\hline
\end{tabular}

Fonte: $\mathrm{O}$ autor. 
Estudo dos impactos da Resolução Normativa no 414/2010 - ANEEL no centro regional de serviço na empresa CEMAT em Tangará da Serra - MT

\subsubsection{Postos de Atendimento ao Público}

Antes da Resolução Normativa n 414/2010, as distribuidoras não tinham obrigação de terem postos de atendimento presencial ao público em todos os municípios de sua concessão. O Centro Regional de Serviço de Tangará da Serra é composto de 27 (vinte e sete) Municípios dos quais somente em 13 (treze) possuíam postos de atendimento local (Tabela 5), ou seja, somente em $48,15 \%$ do total havia atendimento presencial ao público.

Com a nova Resolução, em 2011 ficou determinado que em todos os Municípios da área de concessão, fosse necessário ter pelo menos um posto de atendimento ao público e também postos para arrecadação (pagamento) da fatura. Caso não existisse a concessionária deveria implantar estrutura própria de arrecadação nos Municípios. Desta forma os Municípios do Centro Regional de Serviço de Tangará da Serra contemplados foram: Alto Paraguai, Campos de Júlio, Castanheira, Cotriguaçu, Denise, Juruena, Nova Marilândia, Nortelândia, Novo Horizonte do Norte, Porto dos Gaúchos, Porto Estrela, Santo Afonso e Tabaporã.

Tabela 5 - Comparação entre as Resoluções Normativas de N. ${ }^{\circ}$ 456/2000 e da N..$^{0}$ 414/2010

\begin{tabular}{|c|c|c|}
\hline ASSUNTO & Durante a n. ${ }^{\circ} 456 / 2000$ - Aneel & Após a n. ${ }^{\circ} 414 / 2010$ - Aneel \\
\hline $\begin{array}{c}\text { Postos de } \\
\text { Atendimento ao } \\
\text { Público }\end{array}$ & $\begin{array}{l}\qquad \text { Art. }^{9^{\circ}} \\
\text { A critério de cada distribuidora. }\end{array}$ & $\begin{array}{l}\qquad \text { Art. }^{177^{\circ}} \text { até Art. } \mathbf{1 8 2}^{\circ} \\
\text { As distribuidoras terão que instalar pelo menos } \\
\text { um posto de atendimento presencial em cada } \\
\text { município de sua área de concessão. Onde cada } \\
\text { atendimento não poderá ultrapassar } 45 \text { minutos. }\end{array}$ \\
\hline Tipo de Serviço & ANO 2010 & ANO 2011 \\
\hline Qd. Postos At. Público & 13 & 27 \\
\hline
\end{tabular}

Fonte: $\mathrm{O}$ autor.

4.1.6 Custos Para Instalação e Manutenção dos Novos Postos de Atendimento ao Público

O custo total para implantação e manutenção desses novos postos de atendimento presencial em 2011 foi de $\mathrm{R} \$$ 1.122.260,90 (um milhão cento e vinte e dois mil e duzentos e sessenta reais e noventa centavos) no ano de 2011, conforme (Tabela 6). 
Estudo dos impactos da Resolução Normativa no 414/2010 - ANEEL no centro regional de serviço na empresa CEMAT em Tangará da Serra - MT

Adervaldo Chaves Ribeiro

No ano 2010 o Centro Regional de Serviço de Tangará da Serra gastou R\$ 151.195,20 (cento e cinquenta e um mil e cento e noventa e cinco reais e vinte centavos) com a mão-deobra. Neste ano não havia atendimento presencial ao público, a empresa tinha apenas o custo de leituristas terceirizados que efetuavam as leituras dos medidores e entregas das faturas.

Após Resolução Normativa n 414/2010, o custo total para manutenção dos novos postos de atendimentos passou a ser de $\mathrm{R} \$ 1.094 .192,40$ (um milhão noventa e quatro mil cento e noventa e dois reais e quarenta centavos) que incluiu o pagamento de funcionários para atendimento ao consumidor e execução de serviços (eletricistas), locação de imóveis e contratação de Agentes Credenciados (Tabela 6).

Esse custo só não foi maior porque em alguns dos municípios foi possível realizar a contratação dos Agentes Credenciados, que realizam 2 (duas) horas de atendimento diário aos clientes da Cemat nos horários das 14:00 hs às 16:00 hs conforme previsto no Art. 180 da Resolução Normativa n ${ }^{\circ}$ 414/2010 que permite atendimento de apenas 8 (oito) horas semanais em municípios com até 2.000 (dois mil) unidades consumidoras, enquadrando neste artigo os seguintes municípios: Campos de Júlio, Nova Marilândia, Nova Maringá, Novo Horizonte do Norte, Porto Estrela e Santo Afonso (Tabela 6).

Tabela 6 - Custos Para Instalação e Manutenção dos Novos Postos de Atendimento ao Público Após a Resolução Normativa N. ${ }^{\circ}$ 414/2010.

\begin{tabular}{|c|c|c|c|c|}
\hline 1 Investimentos & $\begin{array}{l}\text { Durante n. }^{\circ} \\
\text { 456/2000 Ano } 2010\end{array}$ & $\begin{array}{l}\text { Após a n. }^{\circ} \\
\text { 414/2010 Ano } 2011\end{array}$ & & $\begin{array}{l}\text { nutenção dos } \\
\text { vos Postos de } \\
\text { endimentos } \\
\end{array}$ \\
\hline $\begin{array}{l}\text { 1.1 Infraestrutura: (Ares-Condicionados, } \\
\text { Micros Computadores, Impressoras, } \\
\text { Cadeiras e Mesas) }\end{array}$ & - & $28.068,50 *$ & & - \\
\hline \multicolumn{5}{|l|}{2 Manutenção } \\
\hline $\begin{array}{l}\text { 2.1 Custeio e Manutenção: (Aluguel, } \\
\text { Água, Telefones, Matérias p/ Escritório) }\end{array}$ & - & $16.152,70$ & $\mathrm{R} \$$ & $16.152,70$ \\
\hline 2.2 Agentes Credenciados & - & $4.630,00$ & $\mathrm{R} \$$ & $4.630,00$ \\
\hline 2.3 Leituristas Terceirizados & $12.599,60 * *$ & - & & - \\
\hline 2.4 Leituristas Cemat (Férias e $13^{\circ}$ ) & - & $17.600,00$ & $\mathrm{R} \$$ & $17.600,00$ \\
\hline 2.5 Eletricista Cemat (Férias e $13^{\circ}$ ) & - & $52.800,00$ & $\mathrm{R} \$$ & $52.800,00$ \\
\hline Total Mês & $12.599,60$ & $91.182,70$ & $\mathrm{R} \$$ & $91.182,70$ \\
\hline Total Ano & $151.195,20$ & $1.122 .260,90$ & $\mathrm{R} \$$ & $1.094 .192,40$ \\
\hline
\end{tabular}


Estudo dos impactos da Resolução Normativa no 414/2010 - ANEEL no centro regional de serviço na empresa CEMAT em Tangará da Serra - MT

Adervaldo Chaves Ribeiro

Na tabela 7 é feito a comparação entre as quantidades de serviços realizadas no ano de 2010 e 2011, na qual fica evidenciado que com Resoluções Normativas da n 414/2010 houve a implantação do serviço de vistoria para ligação de Unidade Consumidora que no ano de 2010 não era realizado, o que representou 17.821 (dezessete mil oitocentos de vinte e um mil) serviços adicionais, que deve ser realizado para liberação do pedido de ligação da Unidade Consumidora, que apresentou um crescimento de 5,83\% em relação a 2010. Já para os serviços de Suspensão e Religação de Unidade Consumidora foi percebido uma redução na quantidade que impossibilitou a empresa de efetuar corte de faturas em aberto a mais de 90 (noventa) dias (ANEEL), desta forma reduziu a quantidade de suspensão de fornecimento, que consequentemente influenciou a quantidade de religação. Conforme Tabela 7, é possível notar que foi necessário realizar abertura de 14 (quatorze) novos postos de atendimento ao público em 2011, fazendo o custo para manutenção dos postos de atendimento aumentar 623,69 \% em relação a 2010.

Tabela 7 - Resumo e Comparação de Quantidades de Serviços e o Custos entre os Anos de 2010 e 2011 no Centro Regional de Serviço de Tangará da Serra - MT.

\begin{tabular}{|c|c|c|c|c|}
\hline Tipo de Serviço & Ano de 2010 & Ano de 2011 & $\begin{array}{l}\text { Diferença } \\
\text { Apurada }\end{array}$ & AV \% \\
\hline $\begin{array}{l}\text { Quantidade de Vistoria } \\
\text { para Ligação Unidade } \\
\text { Consumidora }\end{array}$ & 0 & 17.821 & 17.821 & 100 \\
\hline $\begin{array}{l}\text { Quantidade de Ligação de } \\
\text { Unidade Consumidora }\end{array}$ & 15.454 & 16.324 & 870 & 5,63 \\
\hline $\begin{array}{l}\text { Quantidade Suspensão Do } \\
\text { Fornecimento de Unidade } \\
\text { Consumidora }\end{array}$ & 36.551 & 32.248 & (4.303) & $(13,34)$ \\
\hline $\begin{array}{l}\text { Quantidade de Religação } \\
\text { de Unidade Consumidora }\end{array}$ & 47.981 & 43.030 & $(4.951)$ & $(11,50)$ \\
\hline $\begin{array}{l}\text { Quantidade de Postos de } \\
\text { Atendimento ao Público }\end{array}$ & 13 & 27 & 14 & 107,69 \\
\hline $\begin{array}{l}\text { Valor do Custos e } \\
\text { Manutenção dos Postos de } \\
\text { Atendimentos ao Público }\end{array}$ & $151.195,20$ & $1.094 .192,40$ & $942.996,70$ & 623,69 \\
\hline
\end{tabular}

Fonte: $\mathbf{O}$ autor.

\section{CONSIDERAÇÕES FINAIS}

Segundo Silva (2012) as transformações do setor elétrico brasileiro são verdadeiros desafios para os gestores das concessionárias de energia elétricas, tendo que cumprir as leis e 
Estudo dos impactos da Resolução Normativa no 414/2010 - ANEEL no centro regional de serviço na empresa CEMAT em Tangará da Serra - MT

as resoluções normativas estabelecidas, com competitividade e qualidade nos serviços prestados para seus consumidores.

Esta pesquisa apresentou as principais mudanças da Resolução Normativa da $n^{\circ}$ 456/2000 para a Resolução Normativa da n 414/2010 - Aneel, que impactaram diretamente no Centro Regional de Serviço de Tangará da Serra - MT.

Comprovou-se que teve 2 (dois) impactos: redução dos prazos de atendimentos para as execuções dos serviços e a abertura de novos postos de atendimento ao público no Centro Regional de Serviço de Tangará da Serra - MT. Com a abertura de novos postos de atendimento ao público aumentou o custo de manutenção dos mesmos em R \$ 942.996,70 (novecentos e quarenta e dois mil, novecentos e noventa e seis reais e setenta centavos), considerando que deste valor, $\mathrm{R} \$ 633.600,00$ (Seiscentos e trinta e três mil e seiscentos reais), representado por $67,19 \%$ do total foi para o pagamento de novos eletricistas para efetuar as vistorias das novas unidades consumidoras, suspensão de fornecimento, ligação e religação dentro dos novos prazos estabelecidos pela Resolução Normativa n 414/2010 - Aneel.

A abertura de novos postos de atendimentos, traz uma comodidade para os consumidores. O Centro Regional de Serviço de Tangará da Serra - MT, teve um aumento significativo de 107,69\%, passando de 13 (treze) para 27 (vinte e sete) Municípios tendo um representante da empresa Cemat.

Os prazos para a execução dos serviços foram reduzidos significativamente, onde o prazo de uma ligação de um novo consumidor era de até 5 (cinco) dias úteis, passou para 2 (dois) dias úteis na área urbana (Tabela 2), reduzindo 60\% do prazo, mesmo com acréscimo de $5,33 \%$ de novos consumidores, somente $0,037 \%$ do total das unidades foram ligadas com 3 (três) dias, violando o indicador. Para os consumidores industrias, o prazo de 10 (dez) dias úteis, passou para 7 (sete) dias úteis (Tabela 2), reduzindo 30\% do prazo, mesmo com acréscimo de 7,59\%, somente $0,41 \%$ do total das unidades foram ligadas com 8 (oito) dias, violando o indicador. O prazo de religações na área urbana foi reduzido em 50\% (Tabela 4), permanecendo a mesma quantidade de 4 (quatro) religações realizada fora do prazo determinado pela resolução, violando o indicador.

Objetivo geral foi alcançado, pois foram identificados os impactos da implantação da Resolução Normativa no 414/2010 - Aneel, no Centro Regional de Serviço de Tangará da Serra - MT. Sugestão para futuros trabalhos; levantamentos dos custos para manutenção nos carros usados na execução dos serviços no Regional de Serviço de Tangará da Serra - MT. 
Estudo dos impactos da Resolução Normativa no 414/2010 - ANEEL no centro regional de serviço na empresa CEMAT em Tangará da Serra - MT

Adervaldo Chaves Ribeiro

\section{REFERÊNCIAS BIBLIOGRÁFICAS}

ABNT - NBR 6023. Associação Brasileira de Normas Técnicas - Normas Brasileiras Informação e Documentação: Referência - Elaboração. Rio de Janeiro, 2000.

ABNT - NBR 10520: Informações e Documentação - Citações em Documentos Apresentação: Rio de Janeiro, agosto, 2002.

ABNT - NBR ISO 9000:2000 - Sistemas de Gestão da Qualidade - Fundamentos e Vocabulário.

ABNT - NBR ISO 9001: 2008 - Sistema de Gestão da Qualidade - Requisitos. Disponivel em < http://www.simplessolucoes.com.br/blog/wp-content/uploads/ 2009/10/ ABNT-NBR-ISO-9001-2008-para-treinamento-Rev1.pdf>. Acesso em 10 de janeiro de 2012.

ANEEL. Agência Nacional de Energia Elétrica. Contratos de Concessão/Permissão. Disponivel em < http://www.aneel.gov.br/area. cfm?idArea=43\&idPerfil=2>. Acesso em 11 de janeiro de 2012.

Processos n. ${ }^{\circ}$ 48500.004591/04-69 e 48500.003826/04-03. Quarto Termo Aditivo ao Contrato de Concessão de Distribuição no 003/1997 - Aneel, que Celebram a União e a Centrais Elétrica Matogrossenses S.A. - Cemat. Disponivel em <ttp://www3.aneel.gov. br/netacgi/cobaia.exe?s4=contrato+de+concess $\%$ E3o+cemat \&s5=\&l=20\&SECT1=IMAGE \& SECT4=e\&SECT6=HITOFF $\&$ SECT3=PLURON\&SECT2=THESON\&SECT5=BIBL01d $=B$ $\mathrm{IBL} \& \mathrm{p}=3 \& \mathrm{u}=\mathrm{HTTP}: / / \mathrm{www}$.neel.gov.br/bibliotecalpesquisafa.htm $\& \mathrm{r}=0 \& \mathrm{f}=\mathrm{S}>$. Acesso em 04 de janeiro de 2012.

Ata 007/99, de 05 de novembro de 1999. Ata de Audiência Pública. Disponivel em $<$ http://www.aneel.gov.br/aplicacoes/Audiencia_Publica/audiencia_proton/1999/AP007_1999 .pdf $>$. Acesso em 10 de janeiro de 2012.

Resolução Aneel nº 024, de 27 de janeiro 2000. Estabelece as Disposições Relativas à Continuidade da Distribuição de Energia Elétrica às Unidades Consumidoras.

Disponivel em <http://www.aneel.gov.br/cedoc/res2000024.pdf >.Acesso em 10 de janeiro de 2012.

Resolução Normativa no 456/2000, de 29 novembro de 2000. Estabelece, de Forma Atualizada e Consolidada, as Condições Gerais de Fornecimento de Energia Elétrica. Disponível em <http://www.aneel.gov.br/cedoc/res2000456.pdf >. Acesso em 04 de janeiro de 2012.

Por Dentro da Conta de Luz: Informação de Utilidade Pública . $4^{\mathrm{a}}$ ed. Brasília. Outubro de 2008. Disponível em <http://www.aneel.gov.br/arquivos/PDF/Cartilha_1p_atual. pdf $>$. Acesso em 04 de março de 2012.

Resolução Normativa $n^{\circ}$ 414/2010, de 09 de setembro de 2010. Estabelece as Condições Gerais de Fornecimento de Energia Elétrica de forma atualizada e 
Estudo dos impactos da Resolução Normativa no 414/2010 - ANEEL no centro regional de serviço na empresa CEMAT em Tangará da Serra - MT

Adervaldo Chaves Ribeiro

consolidada. Disponível em <http://www.aneel.gov.br/cedoc/bren2010414.pdf >. Acesso em 04 de janeiro de 2012.

Prodist - Módulo 8 - Procedimentos de Distribuição de Energia Elétrica no

Sistema Elétrico Nacional - Qualidade da Energia Elétrica, de 01 de janeiro de 2011. $2^{\text {a }}$

Revisão. Disponível em <http://www.aneel.gov.br/arquivos/PDF/Modulo8_Revisao_2.pdf >. Acesso em 19 de janeiro de 2012.

BRASIL. Lei $n^{\circ}$ 8.078, de 11 de setembro de 1990. Dispõe Sobre a Proteção do Consumidor e dá Outras Providências. Disponivel em <http://www.leidireto.com.br/lei8078.html>. Acesso em 04 de janeiro de 2012.

. Lei $n^{\circ}$ 8.631, de 04 de março de 1993. Dispõe Sobre a Fixação dos Níveis das Tarifas Para o Serviço Público de Energia Elétrica, Extingue o Regime de Remuneração Garantida e dá Outras Providências. Disponivel em <http://www.aneel.gov.br/cedoc/blei 19938631.pdf>. Acesso em 04 de janeiro de 2012.

.Lei n ${ }^{\circ}$ 8.987, de 13 de fevereiro de 1995. Dispõe Sobre o Regime de Concessão e Permissão da Prestação de Serviços Públicos Previsto no art. 175 da Constituição Federal, e dá Outras Providências. Disponivel em <http://www.aneel.gov.br/cedoc/blei 19958987.pdf>. Acesso em 04 de janeiro de 2012.

Lei n 9.074, de 07 de julho de 1995. Estabelece Normas Para Outorga e Prorrogações das Concessões e Permissões de Serviços Públicos e dá Outras Providências. Disponivel em <http://www.aneel.gov.br/cedoc/blei19959074.pdf>. Acesso em 04 de janeiro de 2012.

. Lei $\mathrm{n}^{\circ}$ 9.427, de 26 de dezembro de 1996. Institui a ANEEL - Agência Nacional de Energia Elétrica Disciplina o Regime de Concessões de Serviço Público de Energia Elétrica, e dá Outras Providências. Disponível em <http://www.aneel.gov.br/cedoc/lei1996 9427.pdf >. Acesso em 05 de fevereiro de 2012.

BRASIL. Decreto $n^{\circ} 2.335$, de 06 de outubro de 1997. Constitui a Agência Nacional de Energia Elétrica - ANEEL, Autarquia sob Regime Especial, Aprova sua Estrutura Regimental e o Quadro Demonstrativo dos Cargos em Comissão e Funções de Confiança e dá Outras Providências. Disponivel em <http://www.planalto.gov.br/ccivil_03decreto/d23 35.htm>. Acesso em 05 de fevereiro de 2012.

CAPUTO, Geovane Anselmo Silveira. Roselli, Marcio Andrey. Aneel e a Prestação Adequada dos Serviços Públicos de Energia Elétrica. Monografia - Universidade Estadual de Luziâna - GO. 2008.

CEMAT. Centrais Elétricas Matogrossenses S.A. Histórico. Disponivel em < http://www. redenergia.com/concessionarias/cemat/residenciais/a-cemat/ historico.aspx > . Acesso em 02 de fevereiro de 2012.

DI PIETRO, Maria Sylvia Zanelia. Parcerias na Administração Pública: Concessão, Permissão, Franquia, Terceirização e Outras Formas. $8^{a}$ ed. São Paulo. Editora Atlas S.A, 1997. 
Estudo dos impactos da Resolução Normativa no 414/2010 - ANEEL no centro regional de serviço na empresa CEMAT em Tangará da Serra - MT

Adervaldo Chaves Ribeiro

EPE. Empresa de Pesquisa Energética. Resenha Mensal de Mercado de Energia Elétrica. Numero 52. Ano V. Janeiro de 2012. Disponivel em <http://www. epe.gov.br / Resenha Mensal/20120127_1.pdf >. Acesso em 05 de maio de 2012.

FIFA. Portal da Copa. Site do Governo Federal Brasileiro Sobre a Copa do Mundo da FIFA 2014. Disponivel em <http://www.copa2014.gov.br/pt-br/arena/cuiaba>. Acesso em 05 de maio de 2012.

GIL, A. C. Métodos e Técnicas de Pesquisa Social. $2^{\text {a }}$ ed. São Paulo. Editora Atlas S.A, 1989.

IBGE - Instituto Brasileiro de Geografia e Estatística. <http://www.ibge.gov .br/estadosat/ perfil.php?sigla=pr>. Acesso em 20 de março de 2012.

KOHAMA, Heilio. Contabilidade Pública: Teoria e Prática. $10^{a}$ ed. São Paulo. Editora Atlas S.A, 2006.

LAKATOS, Eva Maria. MARCONI, Marina de Andrade. Fundamentos de Metodologia Científica. $7^{a}$ Ed. São Paulo. Editora Atlas S.A, 2010.

MEIRELLES, Hely Lopes. Direito Administrativo Brasileiro. $23^{\text {a }}$ ed. São Paulo. Editora Malheiros Editores 1998.

OLIVEIRA, Silvio Luiz de. Tratado de Metodologia Cientifica: Projetos de Pesquisa; TGI, TCC, Monografias, Dissertações e Teses. Ed. São Paulo. Editora Pioneira S.A, 2002.

PACIEVITCH, Thais. Economia do Estado do Mato Grosso. InfoEscola Navegando e Aprendendo. 15 de outubro de 2008. Disponível em <http://www.infoescola.com/matogrosso/economia-do-mato-grosso/>. Acesso em 06 de maio de 2012.

PIRES, José Cláudio Linhares. O Processo de Reformas do Setor Elétrico Brasileiro. Revista do Bndes. Rio de Janeiro, v. 6, n. 12, p. 137-168, dez. 1999. Disponível em <http:// www.bnds.gov.br/SiteBNDES/export/sites/default/bndes_pt/Galerias/Arquivos/conhecimento /revista/rev1206.pdf>. Acesso em 05 de maio de 2012.

RIBEIRO, Magno Alves; TORRES, Ariel Lopes; ROCHA, Margarida Alves. Manual Para Elaboração e Apresentação de Monografias: com noções introdutórias de metodologia. Tangará da Serra: Unemat, 2006. Acesso em 05 de maio de 2012.

SILVA, Edna Lúcia da; MENEZES, Estera Muszkat. Metodologia da Pesquisa e Elaboração de Dissertação. 3. ${ }^{a}$ Ed. revisada e atualizada. Florianópolis: UFSC, 2001.

SILVA, Sidney Tavares da; Gerência do Centro Regional de Serviço de Tangará da Serra - CRS - TS. Entrevista concedida a Aparecido Marcio Pereira, Tangará da Serra - MT, 06 março. 2012.

VANZELLA, Clailde. Metodologia para implantação da Contabilidade por Atividades em Empresas Distribuidoras de Energia Elétrica. Dissertação de Mestrado em Engenharia 
Estudo dos impactos da Resolução Normativa n 414/2010 - ANEEL no centro regional de serviço na empresa CEMAT em Tangará da Serra - MT

Aparecido Marcio Pereira

Adervaldo Chaves Ribeiro

de Produção - Programa de Pós-Graduação em Engenharia de Produção, UFSC, Florianópolis - SC. 2003. 